\title{
Presenting Characteristics, Comorbidities, and Outcomes Among Patients With COVID-19 Hospitalized in Pakistan: Retrospective Observational Study
}

Hashaam Akhtar ${ }^{1}$, PhD; Sundas Khalid ${ }^{2}$, MPhil; Fazal ur Rahman ${ }^{3}$, MBBS; Muhammad Umar ${ }^{4}$, MBBS; Sabahat Ali ${ }^{5}$, MBBS; Maham Afridi ${ }^{6}$, MPhil; Faheem Hassan ${ }^{7}$, MSc; Yousef Saleh Khader $^{8}$, BDS, MSPH; Nasim Akhtar ${ }^{9}$, MBBS; Muhammad Mujeeb Khan ${ }^{10}$, MBBS; Aamer Ikram ${ }^{11}$, MBBS, PhD

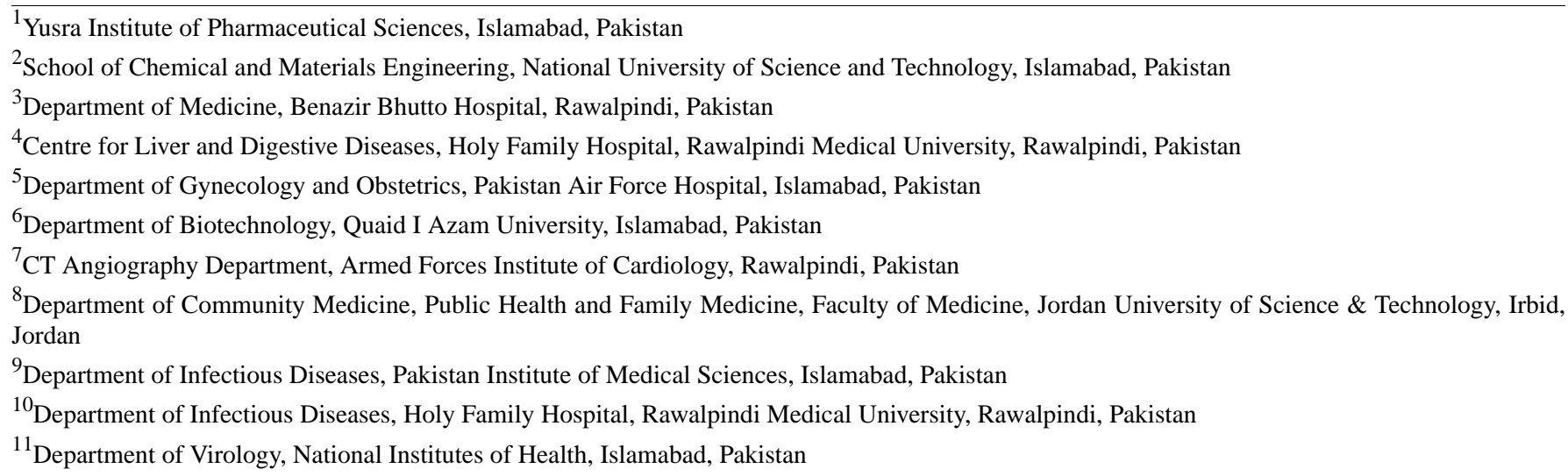

Corresponding Author:

Hashaam Akhtar, PhD

Yusra Institute of Pharmaceutical Sciences

Zaraj Housing Society, Opposite DHA Phase 2 Gate III

Main G T Road

Islamabad, 44000

Pakistan

Phone: 923215272489

Email: hashaamakhtar@gmail.com

\section{Abstract}

Background: COVID-19 became a pandemic rapidly after its emergence in December 2019. It belongs to the coronavirus family of viruses, which have struck a few times before in history. Data based on previous research regarding etiology and epidemiology of other viruses from this family helped played a vital role in formulating prevention and precaution strategies during the initial stages of this pandemic. Data related to COVID-19 in Pakistan were not initially documented on a large scale. In addition, due to a weak health care system and low economic conditions, Pakistan's population, in general, already suffers from many comorbidities, which can severely affect the outcome of patients infected with COVID-19.

Objective: COVID-19 infections are coupled with a manifestation of various notable outcomes that can be documented and characterized clinically. The aim of this study was to examine these clinical manifestations, which can serve as indicators for early detection as well as severity prognosis for COVID-19 infections, especially in high-risk groups.

Methods: A retrospective observational study involving abstraction of demographic features, presenting symptoms, and adverse clinical outcomes for 1812 patients with COVID-19 was conducted. Patients were admitted to the four major hospitals in the Rawalpindi-Islamabad region of Pakistan, and the study was conducted from February to August 2020. Multivariate regression analysis was carried out to identify significant indicators of COVID-19 severity, intensive care unit (ICU) admission, ventilator aid, and mortality. The study not only relates COVID-19 infection with comorbidities, but also examines other related factors, such as age and gender.

Results: This study identified fever (1592/1812, 87.9\%), cough (1433/1812, 79.1\%), and shortness of breath (998/1812, 55.1\%) at the time of hospital admission as the most prevalent symptoms for patients with COVID-19. These symptoms were common 
but not conclusive of the outcome of infection. Out of 1812 patients, $24.4 \%(n=443)$ required ICU admission and $21.5 \%$ ( $n=390)$ required ventilator aid at some point of disease progression during their stay at the hospital; $25.9 \%$ ( $n=469$ ) of the patients died. Further analysis revealed the relationship of the presented symptoms and comorbidities with the progression of disease severity in these patients. Older adult patients with comorbidities, such as hypertension, diabetes, chronic kidney disease, and asthma, were significantly affected in higher proportions, resulting in requirement of ICU admission and ventilator aid in some cases and, in many cases, even mortality.

Conclusions: Older adult patients with comorbidities, such as hypertension, diabetes, asthma, chronic obstructive pulmonary disorder, and chronic kidney disease, are at increased risk of developing severe COVID-19 infections, with an increased likelihood of adverse clinical outcomes.

(JMIR Public Health Surveill 2021;7(12):e32203) doi: 10.2196/32203

\section{KEYWORDS}

COVID-19; indicators; symptoms; risk factors; comorbidities; severity; Pakistan

\section{Introduction}

COVID-19 is a worldwide pandemic that has proliferated across the globe since its spread from Wuhan, China, in December 2019 [1-3]. Since then, full clinical presentations of this viral infection are still not fully understood, as being an RNA virus with many variants, its clinical manifestations are always different [4]. Nevertheless, cough, fever, dyspnea, body ache, fatigue, and pneumonia are some of the most presented symptoms; however, due to its contagious nature and a wide array of asymptomatic, mild to severe, and, in some cases, life-threatening clinical manifestations [5], as well as a dearth of a standardized effective treatment strategies [6], the COVID-19 case count is escalating with time. According to the World Health Organization (WHO), Pakistan hastily entered the race of having the maximum COVID-19 cases per day and could be classified as having Level 4 COVID-19 transmission, where community transmission of the virus is the main reason for increasing COVID-19 cases [7]. Despite its proximity with China, India, and Iran, the total number of confirmed cases in Pakistan has never risen above 7000 per day, and the death toll per day has also been under control [8].

As of December 11, 2020, the total number of COVID-19 cases worldwide was $71,070,927$, with 49,384,495 recoveries; 1,594,772 deaths; and 20,091,660 active cases awaiting outcomes [9]. In Pakistan as of December 11, 2020, the total number of COVID-19 cases was 432,327,149, with 379,092 recoveries; 8653 deaths; and 44,582 active cases awaiting outcomes [8]. The twin cities Rawalpindi and Islamabad in Pakistan have a combined population of around 3 million people and were a hot spot during various waves of COVID-19 [8]. A few small-scale studies have been reported from Pakistan, but there is a dire need to regularly gather, document, and analyze epidemiological data from patients with COVID-19 in Pakistan in a systematic way; this is needed in order to identify high-risk groups and determine risk factors associated with poor disease prognoses, in relation with resultant morbidity or mortality [10-14].

There is a lack of standardized treatment regimens because of varying symptoms associated with COVID-19 infections. The treatment so far has been symptomatic or supportive therapy instead of fixed regimens. A retrospective cohort study on hospitalized patients in China revealed that more men (median age 56 years) than women required intensive care unit (ICU) facilities and had a $28 \%$ mortality rate [15]. Nevertheless, health care conditions, prevalence of comorbidities, and lifestyle in Pakistan are quite different than in other countries, in general. We hereby performed a retrospective analysis study aimed at describing the demographic and clinical characteristics and subsequent clinical outcomes that are associated with COVID-19 infections; our cohort included 1812 cases confirmed by real-time reverse transcription-polymerase chain reaction (rRT-PCR) and that were admitted to the four major hospitals in the Rawalpindi-Islamabad region of Pakistan from February to August 2020. The objective was to identify the clinical outcomes and determine the impact of various factors, such as age, gender, and number and types of underlying comorbidities in patients with COVID-19, that can resultantly contribute to adverse clinical outcomes, including COVID-19 severity, requirement of ICU admission, ventilator aid, and mortality.

We analyzed the characteristics and outcomes of patients; these were correlated with the number and types of comorbidities as indicators of COVID-19 severity and prognostic values in pandemic viral infectious diseases, such as COVID-19. More studies are required to assess the clinical manifestations associated with COVID-19 infections, as well as the time and duration of each symptom after viral invasion, in order to provide concrete data about the course of action needed to counter or avoid symptoms by taking necessary prophylactic steps, especially among high-risk patients.

\section{Methods}

This retrospective study was conducted using clinical data acquired from 1812 patients with confirmed COVID-19 who were admitted to four major tertiary care hospitals in Islamabad-Rawalpindi from February to August 2020. The Islamabad-based hospitals were Pakistan Air Force Hospital and Pakistan Institute of Medical Sciences Hospital; the Rawalpindi-based hospitals were Holy Family Hospital and Benazir Bhutto Shaheed Hospital. The study was approved by the ethics review board of Rawalpindi Medical University before data collection, and the data were collected with approval from the National Institute of Health, Pakistan, by HA and SA. In addition to this, the data were systematically organized and recorded using a standardized data collection form specifically designed for the study. 
Diagnosis of COVID-19 was confirmed using a polymerase chain reaction (PCR) test on nasal and oropharyngeal swab samples taken at the time of admission to the hospital. A detailed medical history was collected for each patient, including age, gender, exposure history, and clinical manifestations of COVID-19, including fever, cough, and respiratory symptoms. A total of 12 comorbidities were each marked as absent or present and these were categorized into four groups: (1) absence of comorbidities, (2) presence of one comorbidity, (3) presence of two comorbidities, and (4) presence of more than two comorbidities. Communicable comorbidities included hepatitis C (Hep C) and tuberculosis (TB). Noncommunicable disease comorbidities included hypertension (HT), diabetes mellitus (DM), cardiovascular diseases (CVDs), asthma, chronic kidney disease (CKD), nervous system disorders (NSDs), chronic obstructive pulmonary disorder (COPD), cancer, allergies, and anemia. A number of other chronic and acute conditions, such as rheumatoid arthritis, typhoid, stomach ulcers, hypothyroidism, and musculoskeletal injuries, were also reported and were grouped together as a 13th category termed "others."

The study was performed in line with the Declaration of Helsinki. Patients with COVID-19 who had immunological diseases or missing data were excluded from the analysis to avoid any confounding factors affecting the inflammatory markers assessed in this study.

COVID-19 severity was classified into two groups based on symptoms of patients within the first week of COVID-19 infection: (1) mild to moderate, including patients with fever, cough, and oxygen saturation of $90 \%$ or greater on room air along with other symptoms consistent with COVID-19, and (2) severe to critical, including patients with dyspnea (ie, oxygen saturation of less than $90 \%$ on room air), pneumonia, and varying degrees of respiratory distress (ie, respiratory rate $>30$ breaths/min), along with other symptoms. Clinical outcomes studied were COVID-19 severity, requirement of ICU admission, requirement of ventilator, and mortality. This classification was based on WHO guidelines regarding the clinical management of patients with COVID-19 [5].

Chest radiographs and computed tomography scans, including presence or absence of ground-glass or crazy-paving appearance, were noted. Moreover, hematological and biochemical parameters, including blood complete picture, serum ferritin, liver function test, creatinine, and a few others, were also recorded to assist in categorizing the patients. PCR test results of the patients and clinical outcomes, such as admission to ICU, requirement for noninvasive or invasive ventilation provided at the hospital at some stage of disease progression, and mortality, were also recorded.

Statistical analysis was conducted using SPSS Statistics for Windows (version 24; IBM Corp). Categorical variables were described using frequencies and percentages. We used $t$ tests to compare two sets of quantitative data. Chi-square tests and Fisher exact tests were used to compare percentages of qualitative variables, where appropriate. Multivariate logistic regression analyses were carried out to determine the indicators of COVID-19 severity and mortality. $P$ values of $<.05$ were considered statistically significant.

\section{Results}

This retrospective study included a total of 1812 patients; $69.2 \%$ $(n=1253)$ of the patients were male. Patients included in the study ranged in age from 1 to 79 years, with a mean age of 47.32 years. The percentage of patients in the severe to critical group increased with age: $9.8 \%$ (31/315) were less than 30 years of age, $59.8 \%$ (177/296) were 60 to 69 years of age, and $74.5 \%$ $(155 / 208)$ were 70 years of age or older. Nevertheless, of the 1812 patients with COVID-19 who were admitted to the one of the four hospitals, upon admission, 1153 (63.6\%) fell into the category of mild to moderate COVID-19 infection, whereas $659(36.4 \%)$ patients fell into the severe to critical category. Of these 659 patients, some went on to require admission to ICU $(n=443)$ or ventilator support $(n=390)$ during their stay at the hospital, some recovered and were discharged, and some passed away ( $n=469)$. Interestingly, we observed equivalent prevalence of male and female patients in the mild to moderate and the severe to critical categories of patients with COVID-19.

In addition to this, regarding the frequency of comorbidities among 1812 patients, 884 patients $(48.8 \%)$ had none, 364 patients $(20.1 \%)$ had one, 335 patients $(18.5 \%)$ had two, and 229 patients $(12.6 \%)$ had more than two. The most prevalent comorbidity was HT ( $\mathrm{n}=625,34.5 \%)$, followed by DM ( $\mathrm{n}=532$, $29.4 \%)$, CVDs $(n=243,13.4 \%)$, asthma ( $n=93,5.1 \%)$, CKD $(\mathrm{n}=93,5.1 \%)$, Hep C $(\mathrm{n}=84,4.6 \%)$, TB $(\mathrm{n}=35,1.9 \%)$, NSDs $(n=30,1.7 \%)$, COPD $(n=18,1.0 \%)$, cancer $(n=13,0.7 \%)$, allergies $(n=13,0.7 \%)$, and anemia $(n=12,0.7 \%)$ (Table 1$)$.

Moreover, the prevalence of comorbidity stayed higher than $60 \%$ for all types in the severe to critical COVID-19 infection category. The prevalence was significant for all types of comorbidities included in this study, except for allergies. Surprisingly, only 111 patients out of 884 (12.6\%) with no comorbidities were admitted to hospital or moved into the severe to critical category; this increased to $48.4 \%$ (176/364) for patients with a single comorbidity, $60.9 \%$ (204/335) for patients with two comorbidities, and $72.5 \%$ (166/229) for patients with more than two comorbidities; these results were significant. Table 1 presents the complete picture of COVID-19 severity in patients with respect to age, gender, and the number and types of comorbidities. 
Table 1. Basic demographic characteristics and COVID-19 severity in hospitalized patients.

\begin{tabular}{|c|c|c|c|c|}
\hline \multirow[t]{2}{*}{ Variables } & \multirow[t]{2}{*}{ Total cases $(\mathrm{N}=1812), \mathrm{n}(\%)^{\mathrm{a}}$} & \multicolumn{2}{|c|}{ COVID-19 severity, $\mathrm{n}(\%)^{\mathrm{b}}$} & \multirow[t]{2}{*}{$P$ value } \\
\hline & & Mild to moderate & Severe to critical & \\
\hline Cases $(\mathrm{N}=1812)$ & $1812(100)$ & $1153(63.6)$ & $659(36.4)$ & $N / A^{c}$ \\
\hline \multicolumn{5}{|l|}{ Age (years) } \\
\hline$<30$ & $315(17.4)$ & $284(30.2)$ & $31(9.8)$ & \multirow[t]{5}{*}{$<.001^{\mathrm{d}}$} \\
\hline $30-49$ & $653(36.0)$ & $510(78.1)$ & 143 (21.9) & \\
\hline $50-59$ & $340(18.8)$ & $187(55.0)$ & $153(45.0)$ & \\
\hline $60-69$ & $296(16.3)$ & $119(40.2)$ & $177(59.8)$ & \\
\hline$\geq 70$ & $208(11.5)$ & $53(25.5)$ & $155(74.5)$ & \\
\hline \multicolumn{5}{|l|}{ Gender } \\
\hline Male & $1253(69.2)$ & $801(63.9)$ & $452(36.0)$ & \multirow[t]{2}{*}{.70} \\
\hline Female & $559(30.8)$ & $352(63.0)$ & $207(37.0)$ & \\
\hline \multicolumn{5}{|l|}{ Number of comorbidities } \\
\hline None & $884(48.8)$ & $773(87.4)$ & $111(12.6)$ & \multirow[t]{4}{*}{$<.001$} \\
\hline 1 & $364(20.1)$ & $186(51.1)$ & $176(48.4)$ & \\
\hline 2 & $335(18.5)$ & $131(39.1)$ & $204(60.9)$ & \\
\hline$>2$ & $229(12.6)$ & $63(27.5)$ & $166(72.5)$ & \\
\hline \multicolumn{5}{|l|}{ Type of comorbidity } \\
\hline Hypertension & $625(34.5)$ & $248(39.7)$ & $377(60.3)$ & $<.001$ \\
\hline Diabetes mellitus & $532(29.4)$ & $201(37.8)$ & $331(62.2)$ & $<.001$ \\
\hline Cardiovascular diseases & $243(13.4)$ & $80(32.9)$ & $163(67.1)$ & $<.001$ \\
\hline Asthma & $93(5.1)$ & $29(31.2)$ & $64(68.8)$ & $<.001$ \\
\hline Chronic kidney disease & $93(5.1)$ & $32(34.4)$ & $61(65.6)$ & $<.001$ \\
\hline Hepatitis C & $84(4.6)$ & $33(39.3)$ & $51(60.7)$ & $<.001$ \\
\hline Tuberculosis & $35(1.9)$ & $11(31.4)$ & $24(68.6)$ & $<.001$ \\
\hline Nervous system disorders & $30(1.7)$ & $7(23.3)$ & $23(76.7)$ & $<.001$ \\
\hline Chronic obstructive pulmonary disorder & $18(1.0)$ & $2(11.1)$ & $16(88.9)$ & $<.001$ \\
\hline Cancer & $13(0.7)$ & $4(30.8)$ & $9(69.2)$ & .01 \\
\hline Allergies & $13(0.7)$ & $5(38.5)$ & $8(61.5)$ & .06 \\
\hline Anemia & $12(0.7)$ & $2(16.7)$ & $10(83.3)$ & .001 \\
\hline Others & $84(4.6)$ & $22(26.2)$ & $62(73.8)$ & $<.001$ \\
\hline
\end{tabular}

${ }^{\mathrm{a}}$ Percentages in this column are based on the total number of patients $(\mathrm{N}=1812)$.

${ }^{\mathrm{b}}$ Percentages in these columns are based on the number of patients reported in the respective rows in the "Total cases" column.

${ }^{\mathrm{c}} \mathrm{N} / \mathrm{A}$ : not applicable; a $P$ value was not calculated for this item.

${ }^{\mathrm{d}}$ The $P$ value for a group of variables is reported in the top row of that group.

The frequency of clinical manifestations in the form of fever, cough, dyspnea, anosmia, ageusia, sore throat, and others are shown in Table 2; fever was the most common symptom among 1812 patients $(n=1592,87.9 \%)$, followed by cough $(n=1433$, $79.1 \%)$ and dyspnea $(\mathrm{n}=998,55.1 \%)$. Loss of taste and smell $(\mathrm{n}=809,44.6 \%)$, sore throat $(\mathrm{n}=499,27.5 \%)$, and body aches $(\mathrm{n}=490,27.0 \%)$ were comparatively less prevalent symptoms.

Indicators of severity varied among 1812 patients included in this study. A total of $443(24.4 \%)$ patients required ICU admission, and $390(21.5 \%)$ required ventilator aid at some point of disease progression during their stay at the hospital. Nevertheless, 469 (25.9\%) patients died with or without ICU admission or ventilator aid.

A significant increase in ICU admissions, ventilator aid events, and mortality was observed with an increase in age and number of comorbidities. No significant differences in ICU admission, ventilator aid events, and mortality were observed between males and females. A significant increase in ICU admissions, 
ventilator aid events, and mortality was observed with the presence of any type of studied comorbidity, except for allergies.

Patients with no known comorbidities had minimal requirements for ICU admission $(47 / 884,5.3 \%)$, ventilator aid events (34/884, $3.8 \%)$, and mortality $(50 / 884,5.7 \%)$; these proportions were approximately 10 times higher with patients who had two or more comorbidities. Delving into each type of comorbidity revealed that approximately half of the patients with any type of comorbidity required ICU admission with or without ventilator aid, and a significant number of them expired.

Table 2. Prevalence of reported signs and symptoms in patients with COVID-19 at the time of hospital admission.

\begin{tabular}{ll}
\hline Signs and symptoms & Patients experiencing these signs and symptoms $(\mathrm{N}=1812), \mathrm{n}(\%)$ \\
\hline Chest pain & $45(2.5)$ \\
Headache & $81(4.5)$ \\
Nausea or vomiting & $115(6.3)$ \\
Diarrhea & $130(7.2)$ \\
Flu & $150(8.3)$ \\
Body aches, fatigue, or malaise & $490(27.0)$ \\
Sore throat & $499(27.5)$ \\
Anosmia or ageusia & $809(44.6)$ \\
Dyspnea & $998(55.1)$ \\
Cough & $1433(79.1)$ \\
Fever & $1592(87.9)$ \\
\hline
\end{tabular}

Table 3 shows the clinical outcomes of the hospitalized patients with COVID-19 with respect to age, gender, and number and types of comorbidities.

Multivariate regression analysis was carried out to identify significant indicators of COVID-19 severity, ICU admission, ventilator aid, and mortality. Factors such as age, gender, and number and types of comorbidities were included, except for anemia, which was excluded due to small sample size.

Our results indicate that old age was a significant indicator of COVID-19 severity, ICU admission, ventilator aid, and mortality. Although our data reported a greater number of male patients, male gender had no significant relationship with COVID-19 severity, ICU admission, ventilator aid, and mortality.

In addition, the results of this study revealed that an increase in the number of comorbidities was a significant predictor of

COVID-19 severity, ICU admission, ventilator aid, and mortality. HT, DM, COPD, CKD, and asthma were significant predictors COVID-19 severity, ICU admission, ventilator aid, and mortality. NSDs, on the other hand, were a significant predictor of COVID-19 severity, ICU admission, and mortality, but not ventilator aid. TB was a significant predictor of COVID-19 severity and ICU admission, but not ventilator aid and mortality. In addition, Hep $\mathrm{C}$ and cancer were both significant predictors of ventilator aid and mortality, whereas CVDs were only a significant predictor of mortality. Presence of allergies was not a significant predictor of any of the study outcomes.

Table 4 shows the multivariate analysis of factors associated with COVID-19 severity, ICU admission, ventilator aid, and mortality. 
Table 3. Clinical outcomes of patients with COVID-19.

\begin{tabular}{|c|c|c|c|c|c|c|c|}
\hline Variables & $\begin{array}{l}\text { Total cases } \\
(\mathrm{N}=1812), \mathrm{n}(\%)^{\mathrm{a}}\end{array}$ & $\begin{array}{l}\mathrm{ICU}^{\mathrm{b}} \text { admission, } \\
\mathrm{n}(\%)^{\mathrm{c}}\end{array}$ & $P$ value & $\begin{array}{l}\text { Ventilator aid, } \mathrm{n} \\
(\%)^{\mathrm{c}}\end{array}$ & $P$ value & Mortality, $\mathrm{n}(\%)^{\mathrm{c}}$ & $P$ value \\
\hline Cases $(\mathrm{N}=1812)$ & $1812(100)$ & $443(24.4)$ & $\mathrm{N} / \mathrm{A}^{\mathrm{d}}$ & $390(21.5)$ & N/A & 469 (25.9) & N/A \\
\hline \multicolumn{8}{|l|}{ Age (years) } \\
\hline$<30$ & 315 (17.4) & $22(7.0)$ & $<.001$ & $17(5.4)$ & $<.001$ & $19(6.0)$ & $<.001$ \\
\hline $30-49$ & $653(36.0)$ & $84(12.9)$ & $<.001$ & $75(11.5)$ & $<.001$ & $88(13.5)$ & $<.001$ \\
\hline $50-59$ & $340(18.8)$ & $101(29.7)$ & $<.001$ & $90(26.5)$ & $<.001$ & $100(29.4)$ & $<.001$ \\
\hline $60-69$ & $296(16.3)$ & $126(42.6)$ & $<.001$ & $109(36.8)$ & $<.001$ & $135(45.6)$ & $<.001$ \\
\hline$\geq 70$ & $208(11.5)$ & $110(52.9)$ & $<.001$ & $99(47.6)$ & $<.001$ & $127(61.1)$ & $<.001$ \\
\hline \multicolumn{8}{|l|}{ Gender } \\
\hline Male & $1253(69.2)$ & $297(23.7)$ & $.27^{\mathrm{e}}$ & $263(21.0)$ & .41 & $313(25.0)$ & .19 \\
\hline Female & $559(30.8)$ & $146(26.1)$ & & $127(22.7)$ & & $156(27.9)$ & \\
\hline \multicolumn{8}{|l|}{ Number of comorbidities } \\
\hline None & $884(48.8)$ & $47(5.3)$ & $<.001$ & $34(3.8)$ & $<.001$ & $50(5.7)$ & $<.001$ \\
\hline 1 & $364(20.1)$ & $124(34.4)$ & $<.001$ & $110(30.2)$ & $<.001$ & $126(34.6)$ & $<.001$ \\
\hline 2 & $335(18.5)$ & $141(42.1)$ & $<.001$ & $128(38.2)$ & $<.001$ & $147(43.9)$ & $<.001$ \\
\hline$>2$ & $229(12.6)$ & $131(57.2)$ & $<.001$ & $118(51.5)$ & $<.001$ & $146(63.8)$ & $<.001$ \\
\hline \multicolumn{8}{|l|}{ Type of comorbidity } \\
\hline Hypertension & $625(34.5)$ & $274(43.8)$ & $<.001$ & $245(39.2)$ & $<.001$ & $294(47.0)$ & $<.001$ \\
\hline Diabetes mellitus & $532(29.4)$ & $235(44.2)$ & $<.001$ & 207 (38.9) & $<.001$ & $245(46.1)$ & $<.001$ \\
\hline Cardiovascular diseases & $243(13.4)$ & $123(50.6)$ & $<.001$ & $112(46.1)$ & $<.001$ & $135(55.6)$ & $<.001$ \\
\hline Asthma & $93(5.1)$ & $51(54.4)$ & $<.001$ & $45(48.4)$ & $<.001$ & $53(57.0)$ & $<.001$ \\
\hline Chronic kidney disease & $93(5.1)$ & $50(53.8)$ & $<.001$ & $47(50.5)$ & $<.001$ & $56(60.2)$ & $<.001$ \\
\hline Hepatitis C & $84(4.6)$ & $37(44.0)$ & $<.001$ & $32(38.1)$ & $<.001$ & $44(52.4)$ & $<.001$ \\
\hline Tuberculosis & $35(1.9)$ & $21(60.0)$ & $<.001$ & $17(48.6)$ & $<.001$ & $18(51.4)$ & $<.001$ \\
\hline Nervous system disorders & $30(1.7)$ & $19(63.3)$ & $<.001$ & $16(53.3)$ & $<.001$ & $21(70.0)$ & $<.001$ \\
\hline $\begin{array}{l}\text { Chronic obstructive pulmonary } \\
\text { disorder }\end{array}$ & $18(1.0)$ & $15(83.3)$ & $<.001$ & $16(88.9)$ & $<.001$ & $16(88.9)$ & $<.001$ \\
\hline Cancer & $13(0.7)$ & $7(53.8)$ & .01 & $7(53.8)$ & .004 & $9(69.2)$ & $<.001$ \\
\hline Allergies & $13(0.7)$ & $6(46.2)$ & .07 & $6(46.2)$ & .03 & $6(46.2)$ & .09 \\
\hline Anemia & $12(0.7)$ & $10(83.3)$ & $<.001$ & $10(83.3)$ & $<.001$ & $10(83.3)$ & $<.001$ \\
\hline Others & $84(4.6)$ & $51(60.7)$ & $<.001$ & $48(67.1)$ & $<.001$ & $54(64.3)$ & $<.001$ \\
\hline
\end{tabular}

${ }^{\mathrm{a}}$ Percentages in this column are based on the total number of patients $(\mathrm{N}=1812)$.

${ }^{\mathrm{b}} \mathrm{ICU}$ : intensive care unit.

${ }^{c}$ Percentages in this column are based on the number of patients reported in the respective rows in the "Total cases" column.

${ }^{\mathrm{d}}$ N/A: not applicable; a $P$ value was not calculated for this item.

${ }^{\mathrm{e}}$ The $P$ value for a group of variables is reported in the top row of that group. 
Table 4. Multivariate analysis of factors associated with COVID-19 severity and clinical outcomes of patients with COVID-19.

\begin{tabular}{|c|c|c|c|c|c|c|c|c|}
\hline \multirow[t]{2}{*}{ Covariates } & \multicolumn{2}{|c|}{ COVID-19 severity } & \multicolumn{2}{|l|}{$\mathrm{ICU}^{\mathrm{a}}$ admission } & \multicolumn{2}{|l|}{ Ventilator aid } & \multicolumn{2}{|c|}{ COVID-19 mortality } \\
\hline & $\mathrm{OR}^{\mathrm{b}}(95 \% \mathrm{CI})$ & $P$ value & OR $(95 \% \mathrm{CI})$ & $P$ value & OR $(95 \% \mathrm{CI})$ & $P$ value & OR $(95 \% \mathrm{CI})$ & $P$ value \\
\hline \multicolumn{9}{|l|}{ Age (years) (vs <30 years) } \\
\hline $30-49$ & $1.9(1.2-2.9)$ & .004 & $1.4(0.8-2.4)$ & .19 & $1.6(0.9-2.9)$ & .09 & $1.8(1.0-3.1)$ & .04 \\
\hline $50-59$ & $3.5(2.2-5.6)$ & $<.001$ & $2.6(1.5-4.5)$ & $<.001$ & $2.9(1.7-5.3)$ & $<.001$ & $3.1(1.8-5.6)$ & $<.001$ \\
\hline $60-69$ & $5.1(3.2-8.3)$ & $<.001$ & $3.8(2.2-6.6)$ & $<.001$ & $3.9(2.1-7.0)$ & $<.001$ & $5.4(3.0-9.7)$ & $<.001$ \\
\hline$\geq 70$ & $11.0(6.4-18.7)$ & $<.001$ & $5.9(3.3-10.4)$ & $<.001$ & $6.3(3.4-11.6)$ & $<.001$ & $10.7(5.9-19.5)$ & $<.001$ \\
\hline Gender (male vs female) & $0.9(0.7-1.2)$ & .68 & $1.1(0.8-1.4)$ & .55 & $1.1(0.8-1.4)$ & .71 & $1.2(0.9-1.5)$ & .30 \\
\hline \multicolumn{9}{|c|}{ Number of comorbidities (vs no comorbidities) } \\
\hline 1 & $4.6(3.4-6.2)$ & $<.001$ & $6.9(4.7-10.1)$ & $<.001$ & $8.2(5.3-12.6)$ & $<.001$ & $6.2(4.3-9.0)$ & $<.001$ \\
\hline 2 & $6.8(4.9-9.5)$ & $<.001$ & $8.8(5.9-13.1)$ & $<.001$ & $10.8(7.0-16.7)$ & $<.001$ & $8.2(5.6-12.0)$ & $<.001$ \\
\hline$>2$ & $10.8(7.2-16.0)$ & $<.001$ & $14.9(9.7-23.0)$ & $<.001$ & $17.4(10.8-27.8)$ & $<.001$ & $16.9(11.0-26.1)$ & $<.001$ \\
\hline \multicolumn{9}{|c|}{ Type of comorbidities (yes vs no) } \\
\hline Diabetes mellitus & $2.3(1.7-3.0)$ & $<.001$ & $1.8(1.4-2.4)$ & $<.001$ & $1.7(1.3-2.2)$ & $<.001$ & $1.6(1.2-2.2)$ & $<.001$ \\
\hline Hypertension & $1.9(1.5-2.5)$ & $<.001$ & $2.0(1.5-2.7)$ & $<.001$ & $2.0(1.5-2.7)$ & $<.001$ & $2.0(1.5-2.7)$ & $<.001$ \\
\hline Cardiovascular diseases & $1.4(1.0-2.0)$ & .08 & $1.4(1.0-1.9)$ & .08 & $1.4(1.0-2.0)$ & .054 & $1.5(1.1-2.2)$ & .02 \\
\hline Chronic kidney disease & $2.1(1.3-3.5)$ & .005 & $2.5(1.5-4.1)$ & $<.001$ & $2.7(1.6-4.4)$ & $<.001$ & $3.3(2.0-5.4)$ & $<.001$ \\
\hline Asthma & $2.4(1.4-4.0)$ & .001 & $2.4(1.5-4.0)$ & $<.001$ & $2.1(1.3-3.5)$ & .003 & $2.4(1.5-4.0)$ & $<.001$ \\
\hline Tuberculosis & $2.6(1.1-6.2)$ & .03 & $3.3(1.4-7.5)$ & .005 & $2.1(0.9-4.6)$ & .08 & $1.6(0.7-3.8)$ & .27 \\
\hline Cancer & $3.0(0.7-12.8)$ & .13 & $2.7(0.7-10.1)$ & .15 & $3.3(0.9-12.4)$ & $<.001$ & $6.3(1.5-26.2)$ & .01 \\
\hline Nervous system disorders & $6.7(2.6-17.6)$ & $<.001$ & $6.2(2.7-14.7)$ & $<.001$ & $4.5(2.0-10.4)$ & .82 & $8.5(3.4-21.1)$ & $<.001$ \\
\hline Allergies & $1.0(0.2-4.3)$ & .96 & $0.9(0.2-3.4)$ & .84 & $1.2(0.3-4.5)$ & .54 & $0.7(0.2-2.7)$ & .58 \\
\hline Hepatitis C & $1.4(0.8-2.4)$ & .18 & $1.3(0.8-2.1)$ & .39 & $1.2(0.7-2.0)$ & $<.001$ & $1.8(1.1-3.0)$ & .03 \\
\hline Chronic kidney disease & $8.2(1.7-40.3)$ & .01 & $10.2(2.6-40.3)$ & .001 & $21.7(4.5-104.8)$ & $<.001$ & $17.5(3.6-86.2)$ & $<.001$ \\
\hline Others & $2.8(1.6-5.1)$ & $<.001$ & $2.9(1.7-4.9)$ & $<.001$ & $3.0(1.8-5.1)$ & $<.001$ & $3.2(1.9-5.5)$ & $<.001$ \\
\hline
\end{tabular}

${ }^{\mathrm{a}} \mathrm{ICU}$ : intensive care unit.

${ }^{\mathrm{b}} \mathrm{OR}$ : odds ratio.

\section{Discussion}

\section{Principal Findings}

COVID-19 was declared a pandemic at the start of 2020 after emerging in December 2019 in Wuhan, China [3]. All the information related to COVID-19, including its risk factors, severity, mortality, clinical manifestations, and other complications, was not very clear, especially in Pakistan. We aimed to highlight and discuss some dependent and independent factors related to COVID-19 in this study.

In our study, the most prevalent presenting symptoms at the time of hospital admission were fever, cough, and shortness of breath. Anosmia, ageusia, sore throat, body aches, fatigue, and malaise were relatively less common presenting symptoms, whereas diarrhea, nausea, and vomiting were the least prevalent presenting symptoms reported by patients at the time of admission. One or more comorbidities, especially HT and DM, were more prevalent among older adults according to our results. Mild to moderate COVID-19 symptoms were highly prevalent in younger groups. These findings were in accordance with those of other studies around the world [15-18]. The most prevalent comorbidities were HT, DM, and CVDs, followed by asthma, CKD, Hep C, TB, NSDs, COPD, cancer, allergies, and anemia, among others.

Two of the most significant findings of this study were related to the age and comorbidity of the patients, which can be explained as age-dependent weakened functionality of cell-mediated immunity with a decline in humoral immune support [15]. On the other hand, SARS-CoV-2 enters the host cell via attachment of its structural spike protein to the membrane-bound angiotensin-converting enzyme 2 (ACE-2) receptor of the host [19]. This attachment results in ACE-2 degradation and affects its role in the renin-angiotensin-aldosterone system (RAAS), resulting in abnormalities in maintaining blood pressure and homeostasis of electrolytes in the human body [20]. ACE- 2 also catalyzes the conversion of angiotensin II into angiotensin (1-7), which regulates RAAS in the vasoconstriction of blood vessels, increase of sodium reabsorption in kidneys, and stimulation of 
the hypothalamus, adrenal cortex, and sympathetic nervous system, to activate thirst centers in the brain and increase secretion of antidiuretic hormone, renin, and aldosterone, respectively [21,22]. Pathophysiological changes in RAAS due to distressed ACE-2 levels in patients with comorbid COVID-19 tend to show undesired outcomes, such as high levels of angiotensin II, which leads to angiogenesis, vascular aging, atherosclerosis, inflammation, and fibrosis, leading to diseases like hypertension, renal failure, and cardiac fibrosis [20]. In addition, angiotensin II also interferes with the anti-inflammatory action of insulin, which highlights its deleterious effect in patients with diabetes [23].

Moreover, following cell entry of SARS-CoV-2, a cascade of events leading to replication of viral nucleic acid and release of mature virus particles from the cell ensues, resulting in stimulation of the host's humoral and cellular immunity. Uncontrolled, systemic release of proinflammatory cytokines and chemokines as a part of the host immune response to SARS-CoV-2 infection results in a highly toxic "cytokine storm," or cytokine release syndrome, which is another hallmark of COVID-19 [19]. As a result, severe forms of COVID-19 can be described by three main phases: early infection, involvement of lungs, and systemic inflammation [24]. It can be concluded that factors that contribute to downregulation of ACE-2, dysregulation of RAAS, impairment of B- and T-cell immunity, and development of cytokine release syndrome also contribute to COVID-19 severity, ICU admission, ventilator aid, and mortality [22,24-27].

Similarly, several other meta-analyses reported that HT, DM, CVDs, and CKD were independent risk factors in patients with COVID-19 and indicators of poor prognosis [4,17,28,29]. A few small-scale studies from Pakistan investigating COVID-19 severity and mortality also reported similar trends [10-14]. Moreover, our findings are also in line with a few initial epidemiological reports from Wuhan, China, as well as more recent studies investigating the impact of comorbidities on patients with COVID-19 from China, the United States, the United Kingdom, Egypt, Spain, and Italy [17,18,30-36].

Multivariate analysis of results revealed that increased age of patients and the number of comorbidities were significantly associated with increased odds of COVID-19 severity, ICU admission, ventilator aid, and mortality. This establishes the fact that older patients with underlying conditions are not only at a higher risk of developing infection, but may also be at risk of severe progression that requires ventilator aid, which may result in death. No significant differences were found between males and females with respect to the odds of COVID-19 severity, ICU admission, ventilator aid, and mortality. Although HT and DM were the most prevalent among all comorbidities studied, with proportions of $34.5 \%$ and $29.4 \%$, respectively, the mortality rates for all comorbidities were significantly higher, and were higher still among patients with two or more comorbidities, with an odds ratio (OR) of 16.9. Nevertheless, all comorbidities examined in this study had relatively higher ORs with respect to ICU admission, ventilator aid, and mortality, emphasizing the importance of considering these factors during COVID-19 treatment protocols.

In short, the COVID-19-associated downregulation of ACE-2, leading to an imbalance of RAAS, combined with an age-dependent impaired immune response and chronic inflammation in older patients, may lead to adverse clinical outcomes. Moreover, the likelihood of the presence of one or multiple chronic underlying comorbidities also increases with age, which may further contribute to a poor prognosis for older patients with COVID-19. Our findings are in line with several studies that have established old age to be a significant predictor of COVID-19 severity, ICU admission, ventilator aid, and mortality [15,37].

\section{Conclusions}

The ever-evolving nature of viruses makes them a difficult target for drug design and targeted therapies. In such confusing times, large studies monitoring several factors that might be associated in disease progression and severity are important for clarifying the picture and helping in the development of effective and targeted drugs and vaccines. Moreover, such studies help in the identification of high-risk groups that might have a more severe disease progression and may need a different treatment regime than others. In the current situation, most of the major government directives and guidelines are designed to help curtail the number of COVID-19 cases. These measures are focused on the following: (1) preventive strategies to control the rate of infection, where people are encouraged to take suitable preventative measures, such as improvement of hand hygiene, use of facial masks, and social distancing, and (2) management strategies, where patients who test positive with COVID-19 and report mild to moderate symptoms are directed to follow isolation protocols at home, are directed to monitor their progress by themselves while staying in contact with health care workers remotely via telephone, and are encouraged to report to hospitals only if severe symptoms manifest [38,39]. Studies that help in the identification of indicators for COVID-19 severity and mortality, specific to the Pakistani population, can help in the development of more refined public awareness programs and preventive strategies to encourage people who belong to high-risk groups to take more stringent preventive measures. Moreover, more sophisticated management strategies can be developed to evaluate risk assessment and ensure that high-risk groups can be identified in time and receive appropriate medical care when required, thereby helping to reduce the overall burden of disease on our already-weak health care infrastructure [40].

\section{Conflicts of Interest}

None declared.

\section{References}


1. Wang W, Tang J, Wei F. Updated understanding of the outbreak of 2019 novel coronavirus (2019-nCoV) in Wuhan, China. J Med Virol 2020 Apr;92(4):441-447 [FREE Full text] [doi: 10.1002/jmv.25689] [Medline: 31994742]

2. Zhi N, Mo Q, Yang S, Qin Y, Chen H, Wu Z, et al. Treatment of pulmonary fibrosis in one convalescent patient with corona virus disease 2019 by oral traditional Chinese medicine decoction: A case report. J Integr Med 2021 Mar;19(2):185-190 [FREE Full text] [doi: 10.1016/j.joim.2020.11.005] [Medline: $\underline{33349611]}$

3. Cucinotta D, Vanelli M. WHO declares COVID-19 a pandemic. Acta Biomed 2020 Mar 19;91(1):157-160 [FREE Full text] [doi: 10.23750/abm.v91i1.9397] [Medline: 32191675]

4. Ssentongo P, Ssentongo AE, Heilbrunn ES, Ba DM, Chinchilli VM. Association of cardiovascular disease and 10 other pre-existing comorbidities with COVID-19 mortality: A systematic review and meta-analysis. PLoS One 2020;15(8):e0238215 [FREE Full text] [doi: 10.1371/journal.pone.0238215] [Medline: 32845926]

5. World Health Organization. Clinical Management of COVID-19: Interim Guidance, 27 May 2020. Geneva, Switzerland: World Health Organization; 2020 May 27. URL: https://apps.who.int/iris/bitstream/handle/10665/332196/ WHO-2019-nCoV-clinical-2020.5-eng.pdf?sequence=1\&isAllowed=y [accessed 2021-12-09]

6. Jean S, Lee P, Hsueh P. Treatment options for COVID-19: The reality and challenges. J Microbiol Immunol Infect 2020 Jun;53(3):436-443 [FREE Full text] [doi: 10.1016/j.jmii.2020.03.034] [Medline: 32307245]

7. World Health Organization. Coronavirus Disease (COVID-19): Situation Report- 111. Geneva, Switzerland: World Health Organization; 2020 May 10. URL: https://www.who.int/docs/default-source/coronaviruse/situation-reports/ 20200510covid-19-sitrep-111.pdf?sfvrsn=1896976f 6 [accessed 2021-12-09]

8. Pakistan cases details. Government of Pakistan. URL: https://covid.gov.pk/stats/pakistan [accessed 2021-12-11]

9. COVID-19 coronavirus pandemic. Worldometer. URL: https://www.worldometers.info/coronavirus/ [accessed 2021-12-11]

10. Asghar MS, Haider Kazmi SJ, Ahmed Khan N, Akram M, Ahmed Khan S, Rasheed U, et al. Clinical profiles, characteristics, and outcomes of the first 100 admitted COVID-19 patients in Pakistan: A single-center retrospective study in a tertiary care hospital of Karachi. Cureus 2020 Jun 20;12(6):e8712 [FREE Full text] [doi: 10.7759/cureus.8712] [Medline: 32699707 ]

11. Abbas S, Zareen S, Saleem S, Tahir A, Rasheed A, Sajid A. Co-morbidities in fatal cases of SARS-Cov-2 in Rawalpindi/Islamabad, Pakistan. Pak Armed Forces Med J 2020;70(1):S232-S236 [FREE Full text]

12. Chaudhry A, Ikram A, Baig A, Salman M, Ghafoor T, Hussain Z, et al. Mortality analysis of COVID-19 confirmed cases in Pakistan. Int J Front Sci 2020 Sep 04;4(2):81-84. [doi: 10.37978/tijfs.v4i2.291]

13. Khan M, Khan H, Khan S, Nawaz M. Epidemiological and clinical characteristics of coronavirus disease (COVID-19) cases at a screening clinic during the early outbreak period: A single-centre study. J Med Microbiol 2020 Aug;69(8):1114-1123 [FREE Full text] [doi: 10.1099/jmm.0.001231] [Medline: 32783802]

14. Shahid R, Umar M, Zafar RB, Zeb S, Ambreen S, Akram MO. Comorbidity of COVID-19 related fatalities in tertiary care hospitals of Rawalpindi, Pakistan. J Rawalpindi Med Coll 2020 Jul 17;24(Supp-1):32-36. [doi: 10.37939/jrmc.v24isupp-1.1422]

15. Zhou F, Yu T, Du R, Fan G, Liu Y, Liu Z, et al. Clinical course and risk factors for mortality of adult inpatients with COVID-19 in Wuhan, China: A retrospective cohort study. Lancet 2020 Mar 28;395(10229):1054-1062 [FREE Full text] [doi: 10.1016/S0140-6736(20)30566-3] [Medline: 32171076]

16. Liu K, Chen Y, Lin R, Han K. Clinical features of COVID-19 in elderly patients: A comparison with young and middle-aged patients. J Infect 2020 Jun;80(6):e14-e18 [FREE Full text] [doi: 10.1016/j.jinf.2020.03.005] [Medline: $\underline{32171866]}$

17. Ghweil AA, Hassan MH, Khodeary A, Mohamed AO, Mohammed HM, Abdelazez AA, et al. Characteristics, outcomes and indicators of severity for COVID-19 among sample of ESNA Quarantine Hospital's patients, Egypt: A retrospective study. Infect Drug Resist 2020;13:2375-2383 [FREE Full text] [doi: 10.2147/IDR.S263489] [Medline: 32765012]

18. Richardson S, Hirsch JS, Narasimhan M, Crawford JM, McGinn T, Davidson KW, The Northwell COVID-19 Research Consortium, et al. Presenting characteristics, comorbidities, and outcomes among 5700 patients hospitalized with COVID-19 in the New York City area. JAMA 2020 May 26;323(20):2052-2059 [FREE Full text] [doi: 10.1001/jama.2020.6775] [Medline: 32320003]

19. Li X, Geng M, Peng Y, Meng L, Lu S. Molecular immune pathogenesis and diagnosis of COVID-19. J Pharm Anal 2020 Apr;10(2):102-108 [FREE Full text] [doi: 10.1016/j.jpha.2020.03.001] [Medline: 32282863]

20. Dandona P, Dhindsa S, Ghanim H, Chaudhuri A. Angiotensin II and inflammation: The effect of angiotensin-converting enzyme inhibition and angiotensin II receptor blockade. J Hum Hypertens 2007 Jan;21(1):20-27. [doi: 10.1038/sj.jhh.1002101] [Medline: 17096009 ]

21. Chappell MC, Marshall AC, Alzayadneh EM, Shaltout HA, Diz DI. Update on the angiotensin converting enzyme 2-angiotensin (1-7)-MAS receptor axis: Fetal programing, sex differences, and intracellular pathways. Front Endocrinol (Lausanne) 2014 Jan 09;4:201 [FREE Full text] [doi: 10.3389/fendo.2013.00201] [Medline: 24409169]

22. Sarzani R, Giulietti F, Di Pentima C, Giordano P, Spannella F. Disequilibrium between the classic renin-angiotensin system and its opposing arm in SARS-CoV-2-related lung injury. Am J Physiol Lung Cell Mol Physiol 2020 Aug 01;319(2):L325-L336 [FREE Full text] [doi: 10.1152/ajplung.00189.2020] [Medline: 32639866]

23. Wiese OJ, Allwood BW, Zemlin AE. COVID-19 and the renin-angiotensin system (RAS): A spark that sets the forest alight? Med Hypotheses 2020 Nov;144:110231 [FREE Full text] [doi: 10.1016/j.mehy.2020.110231] [Medline: 33254538] 
24. Lanza K, Perez LG, Costa LB, Cordeiro TM, Palmeira VA, Ribeiro VT, et al. COVID-19: The renin-angiotensin system imbalance hypothesis. Clin Sci (Lond) 2020 Jun 12;134(11):1259-1264 [FREE Full text] [doi: 10.1042/CS20200492] [Medline: $\underline{\text { 32507883] }}$

25. Abassi Z, Higazi AAR, Kinaneh S, Armaly Z, Skorecki K, Heyman SN. ACE2, COVID-19 infection, inflammation, and coagulopathy: Missing pieces in the puzzle. Front Physiol 2020;11:574753 [FREE Full text] [doi: 10.3389/fphys.2020.574753] [Medline: 33123031]

26. Zhang X, Li S, Niu S. ACE2 and COVID-19 and the resulting ARDS. Postgrad Med J 2020 Jul;96(1137):403-407. [doi: 10.1136/postgradmedj-2020-137935] [Medline: 32522846]

27. Mascolo A, Scavone C, Rafaniello C, Ferrajolo C, Racagni G, Berrino L, et al. Renin-angiotensin system and coronavirus disease 2019: A narrative review. Front Cardiovasc Med 2020;7:143 [FREE Full text] [doi: 10.3389/fcvm.2020.00143] [Medline: 32850989]

28. Zaki N, Alashwal H, Ibrahim S. Association of hypertension, diabetes, stroke, cancer, kidney disease, and high-cholesterol with COVID-19 disease severity and fatality: A systematic review. Diabetes Metab Syndr 2020;14(5):1133-1142 [FREE Full text] [doi: 10.1016/j.dsx.2020.07.005] [Medline: $\underline{\text { 32663789] }}$

29. Aly MH, Rahman SS, Ahmed WA, Alghamedi MH, Al Shehri AA, Alkalkami AM, et al. Indicators of critical illness and predictors of mortality in COVID-19 patients. Infect Drug Resist 2020;13:1995-2000 [FREE Full text] [doi:

10.2147/IDR.S261159] [Medline: 32617010]

30. Chen N, Zhou M, Dong X, Qu J, Gong F, Han Y, et al. Epidemiological and clinical characteristics of 99 cases of 2019 novel coronavirus pneumonia in Wuhan, China: A descriptive study. Lancet 2020 Feb 15;395(10223):507-513 [FREE Full text] [doi: 10.1016/S0140-6736(20)30211-7] [Medline: 32007143]

31. Huang C, Wang Y, Li X, Ren L, Zhao J, Hu Y, et al. Clinical features of patients infected with 2019 novel coronavirus in Wuhan, China. Lancet 2020 Feb 15;395(10223):497-506 [FREE Full text] [doi: 10.1016/S0140-6736(20)30183-5] [Medline: $\underline{31986264]}$

32. Yang J, Zheng Y, Gou X, Pu K, Chen Z, Guo Q, et al. Prevalence of comorbidities and its effects in patients infected with SARS-CoV-2: A systematic review and meta-analysis. Int J Infect Dis 2020 May;94:91-95 [FREE Full text] [doi: 10.1016/j.ijid.2020.03.017] [Medline: 32173574]

33. Guan W, Liang W, Zhao Y, Liang H, Chen Z, Li Y, China Medical Treatment Expert Group for COVID-19. Comorbidity and its impact on 1590 patients with COVID-19 in China: A nationwide analysis. Eur Respir J 2020 May;55(5):2000547 [FREE Full text] [doi: 10.1183/13993003.00547-2020] [Medline: 32217650]

34. Docherty AB, Harrison EM, Green CA, Hardwick HE, Pius R, Norman L, ISARIC4C Investigators. Features of 20133 UK patients in hospital with COVID-19 using the ISARIC WHO Clinical Characterisation Protocol: Prospective observational cohort study. BMJ 2020 May 22;369:m1985 [FREE Full text] [doi: 10.1136/bmj.m1985] [Medline: $\underline{\text { 32444460] }}$

35. Rodríguez-Molinero A, Gálvez-Barrón C, Miñarro A, Macho O, López GF, Robles MT, COVID-19 Research Group of CSAPG. Association between COVID-19 prognosis and disease presentation, comorbidities and chronic treatment of hospitalized patients. PLoS One 2020;15(10):e0239571 [FREE Full text] [doi: 10.1371/journal.pone.0239571] [Medline: 33057443]

36. Grasselli G, Greco M, Zanella A, Albano G, Antonelli M, Bellani G, COVID-19 Lombardy ICU Network. Risk factors associated with mortality among patients with COVID-19 in intensive care units in Lombardy, Italy. JAMA Intern Med 2020 Oct 01;180(10):1345-1355 [FREE Full text] [doi: 10.1001/jamainternmed.2020.3539] [Medline: $\underline{32667669}$ ]

37. Petrilli CM, Jones SA, Yang J, Rajagopalan H, O'Donnell L, Chernyak Y, et al. Factors associated with hospital admission and critical illness among 5279 people with coronavirus disease 2019 in New York City: Prospective cohort study. BMJ 2020 May 22;369:m1966 [FREE Full text] [doi: 10.1136/bmj.m1966] [Medline: $\underline{\text { 32444366] }}$

38. Atif M, Malik I. Why is Pakistan vulnerable to COVID-19 associated morbidity and mortality? A scoping review. Int J Health Plann Manage 2020 Sep;35(5):1041-1054 [FREE Full text] [doi: 10.1002/hpm.3016] [Medline: $\underline{32700410]}$

39. Siam M, Nishat NH, Ahmed A, Hossain MS. Stopping the COVID-19 pandemic: A review on the advances of diagnosis, treatment, and control measures. J Pathog 2020;2020:9121429 [FREE Full text] [doi: 10.1155/2020/9121429] [Medline: 33133697]

40. World Health Organization. WHO Country Cooperation Strategy at a Glance: Pakistan. Geneva, Switzerland: World Health Organization; 2018 May 01. URL: https://www.who.int/publications/i/item/WHO-CCU-18.02-Pakistan [accessed 2020-12-22]

\section{Abbreviations}

ACE-2: angiotensin-converting enzyme 2

CKD: chronic kidney disease

COPD: chronic obstructive pulmonary disorder

CVD: cardiovascular disease

DM: diabetes mellitus

Hep C: hepatitis C

HT: hypertension 
ICU: intensive care unit

NSD: nervous system disorder

OR: odds ratio

PCR: polymerase chain reaction

RAAS: renin-angiotensin-aldosterone system

rRT-PCR: real-time reverse transcription-polymerase chain reaction

TB: tuberculosis

WHO: World Health Organization

\author{
Edited by M Alyahya; submitted 19.07.21; peer-reviewed by DW Han, $R$ Mirzaei; comments to author 25.07.21; revised version \\ received 04.10.21; accepted 25.10.21; published 14.12 .21 \\ Please cite as: \\ Akhtar H, Khalid S, Rahman FU, Umar M, Ali S, Afridi M, Hassan F, Saleh Khader Y, Akhtar N, Khan MM, Ikram A \\ Presenting Characteristics, Comorbidities, and Outcomes Among Patients With COVID-19 Hospitalized in Pakistan: Retrospective \\ Observational Study \\ JMIR Public Health Surveill 2021;7(12):e32203 \\ URL: https://publichealth.jmir.org/2021/12/e32203 \\ doi: $10.2196 / 32203$ \\ PMID: $\underline{34710053}$
}

CHashaam Akhtar, Sundas Khalid, Fazal ur Rahman, Muhammad Umar, Sabahat Ali, Maham Afridi, Faheem Hassan, Yousef Saleh Khader, Nasim Akhtar, Muhammad Mujeeb Khan, Aamer Ikram. Originally published in JMIR Public Health and Surveillance (https://publichealth.jmir.org), 14.12.2021. This is an open-access article distributed under the terms of the Creative Commons Attribution License (https://creativecommons.org/licenses/by/4.0/), which permits unrestricted use, distribution, and reproduction in any medium, provided the original work, first published in JMIR Public Health and Surveillance, is properly cited. The complete bibliographic information, a link to the original publication on https://publichealth.jmir.org, as well as this copyright and license information must be included. 